\title{
RESTART ROMANIA'S AGRICULTURE - A PART OF THE COUNTRY'S SURVIVAL STRATEGY IN TIMES OF CRISIS
}

\author{
Constantin-Iulian TĂNAȘCU ${ }^{a *}$, Cristina STATE ${ }^{b}$, Alina-Nicoleta BÎRSAN ${ }^{c}$ \\ ${ }^{a, b, c}$ Bucharest University of Economic Studies, Romania
}

\begin{abstract}
Agriculture is an important subject when it comes to the survival of a nation. We all saw how a pandemic crisis, out of nowhere, can easily disrupt and affect not just the food industry as a whole, but entire the mentality of people all around the Globe. The lack of response in the food industry towards supply chains combined with fear for lack of resources created a mass panic that people might not have access to enough goods to feed their families.

Therefore, we conducted a study between 4th of March and 1st of June 2020 and took in consideration reports from National Institute of Statistics, various Governmental and agricultural research papers published in this timeframe, along with an online questionnaire addressed to farmers. The implied research methodology in achieving the expressed objectives of the study consisted in a quantitative research through a survey supported via an online questionnaire. The analysis of the data collected through the questionnaire was done using techniques such as frequency of answers to questions addressed to participants in the study. We have noticed that farmers are producing important quantities of goods, but they cannot sell them in markets or supermarkets. In other words, there are loads of products to satisfy consumption needs of the population, but those products don't leave gardens or greenhouses.

This is the main reason why we intend to extend the study in the near future to verify if this situation is being generated by lack of interest from the Government or from small or medium farmers. Nevertheless, we are aware of the limitations of our study. Thus, we consider that its addressability is rather restricted. The group of respondents included both young and mature farmers, some of them with a low level of digital skills. On the other hand, the respondents had not been previously selected so that there is the risk that expressed points of view would be based not just on experience, but also on intuition.
\end{abstract}

KEYWORDS: agriculture, crisis, solutions, farmers, farmland, food industry

\section{INTRODUCTION}

Romania can be considered one of the luckiest countries in the world if we are talking about agriculture. Even when we take into consideration climate or geographical position of our country, Romania is lucky and rich in loads of factors that can positively influence the agricultural sector. Romania is situated in the south-eastern part of Central Europe, inside the Carpathians Arch on Danube's lower course with exit to the Black Sea. There is a good distribution when it comes to the topography since mountains account for $31 \%$ of the country's territory, hills and plateaus occupying $36 \%$, meadows and plains covering 33\%.

The climate is a transitional temperate continental with oceanic influences, Mediterranean and excessive continental ones. This variation of climates is caused by geographical elements that determine temperatures to be registered between $0-2.6^{\circ} \mathrm{C}$ during winter and between $35-41^{\circ} \mathrm{C}$

\footnotetext{
${ }^{*}$ Corresponding author. E-mail address: tc_iulian@yahoo.com
} 
during summer. According to Petrescu et al. (2014) all climate changes that took part in Romania in the last few years like tornadoes, floods and intense cloud to ground strokes and severe winds had significant effects in all economic sectors, but mostly in the agricultural one which is deeply influenced by weather conditions.

According to Trușcă and Alecu (2005) every physical, biological and chemical process that determines growth and/or development of crops is assigned to specific climatic demands and any deviation from those demands can determine large variability with major negative consequences on food security. According to National Institute of Statistics (2015) during years with severe droughts, a very small number of yields was obtained (below $1000 \mathrm{~kg} / \mathrm{ha}$ ) with a substantial decrease of 60$70 \%$ from agricultural areas production potential and, sometimes, because of natural disasters, the yields were totally destroyed.

The agricultural sector doesn't need to overcome just the climate change challenges but also the quality of the farmland, the number of people who need to be fed or the farmers' own professional challenges. According to Vincze and Kerekes (2009) Romania owns $238.391 \mathrm{~km} 2$ (9 ${ }^{\text {th }}$ place in EU). Land itself represents the most important Romanian natural resource (including land plots) regardless of their use. The agricultural land represents $62 \%$ of the total surface available for agriculture but it decreases slowly each year. Also, Romania has, according to the National Institute of Statistics (2019) arable areas represent 39.2\% (63\% from the total agricultural), $28 \%$ forests, $20.5 \%$ hayfields and pastures, $2.3 \%$ orchards and vineyards, $3.7 \%$ ponds and waters and $1.8 \%$ other areas. Romania has a population of 20.4 million (2018) which means that it holds the $7^{\text {th }}$ place in EU, though it decreases constantly due to migration, thus the labor force involved in agricultural jobs decreasing to $28.8 \%$. Nevertheless, this decrease in population signifies fewer people both to be fed but also available to work in the agricultural sector, despite the Asian migrants coming to Romania. To these challenges the negative natural growth of Romanian population can also be added, not to mention decreased interest in the agricultural sector.

2020 represents a pandemic year, one important to all of us since food stocks were at a lower level than normal and people working in agriculture were unable to provide the products the markets demanded in the required record time the fast-purchasing cycle imposed. More than that, Romania came to realize the there are some notable problems with its arable land since it is not entirely used to produce grains or other products that could ensure its people a better living in times of pandemic. Another challenging issue underlined by the pandemic was the national irrigation system, many regions lacking such systems, therefore harvests suffering from draught and farmers being forced to pay more to protect their lands.

After the first wave of the pandemic was overcome, farmers concluded that, without Governmental help it's impossible for them to provide the necessary goods to feed so many people. Thus, the population should pay more for the same amount of food. More than that, due to delayed Governmental support or lack of it numerous businesses based on agriculture will be forced to restructure or declare bankruptcy in the nearest future, even close.

The paper illustrates the fact that, year on year, problems identified during this pandemic will not cease to grow until they reach a maximum level when we will have to deal with the incapacity of providing food or products from self-production. The authors proposed the following research objectives:

- To identify farmland problems based on farmers' opinions;

- To present the benefits of developing a nationally available integrated irrigation systems to service all Romanian farmland;

- To propose sustainable improvement solutions for the Romanian agricultural sector. 


\section{RESEARCH METHODOLOGY}

In order to analyze the pandemic impact on agriculture and assess the problems Romanian farmers are facing, the authors performed a quantitative analysis by talking to farmers, who also filled in a questionnaire that will help the authors come up with possible answers to (questionnaire) identified issues. For data examination, authors are looking to identify a trend that will show the problem and will make clear the impact.

It is highly important to emphasize that the agricultural sector is of utmost importance for any country, not only for European Union Member States, but in the World. A lack of products from agriculture industry or an underperforming industry can be translated as a lot of money spent from the treasury for buying products from other countries and a failure when it comes to using the country's surface resources.

\section{THEORETICAL UNDERPINNINGS}

As mentioned by Ciutacu et al. (2015), it is known that the agriculture of every country was before any other industry, the builder and the architect of the cultural, moral and social structures when it comes to the world's nations. In Eastern Europe, according to Filon (2012), the products resulted from agriculture were structured based on the principle of collective ownership, with the respect for the principle of the capital of surplus being channeled to the state management authorities. Nowadays everything has changed and Eastern countries are trying to make a powerful agriculture based of globalization's standards. Romanian agriculture occupies an important place in the European agriculture, being on the $6^{\text {th }}$ place when it comes to the size of the agricultural surface, using almost 13.9 million ha. in 2017. A size bigger than the arable fields in Romania can be seen in France, Spain, UK, Germany and Poland. The situation of arable fields can be seen in figure 1 .

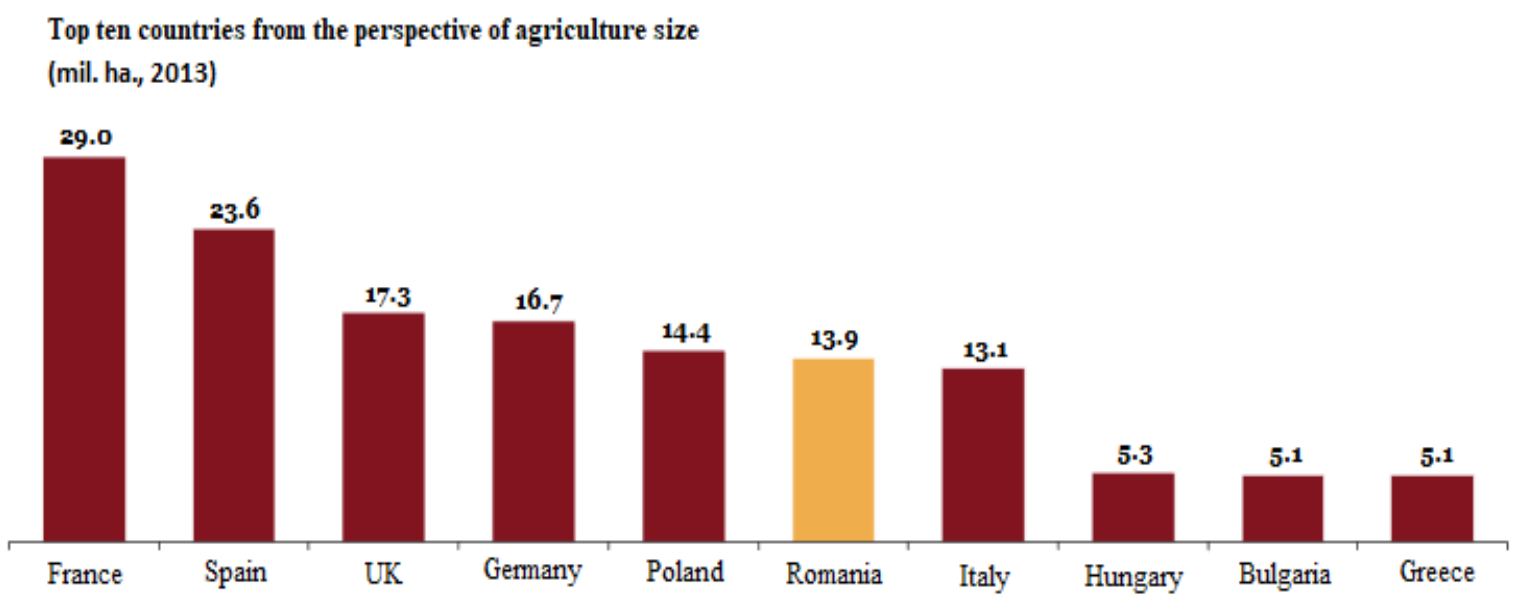

Figure 1. Top ten countries from the perspective of agriculture size

Source: The development potential of the agricultural sector in Romania 2017 - PWC report, p. 4

Out of the total used agricultural land, approximately $60 \%$ ( 8.2 million ha) is cultivated arable land; of this area, about $66 \%$ (5.4 million ha) is cultivated with cereals, mainly wheat and corn. Other uses of the used agricultural area include animal husbandry, animal pastures, hayfields, etc. The average annual value of Romanian agricultural production during 2015-2017 was about EUR 15 billion, with significant differences registered during weak agricultural years. The Romania's agriculture industry can be seen in the Figure 2. 
Agricultural land used by the type of culture (mil.ha, 2019)

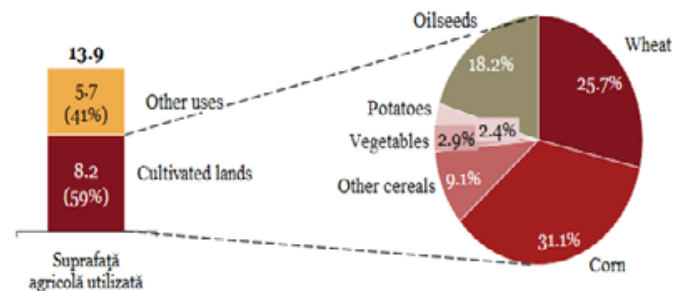

The evolution of the total value of agricultural production (EUR mld, base prices, 2013-2019)

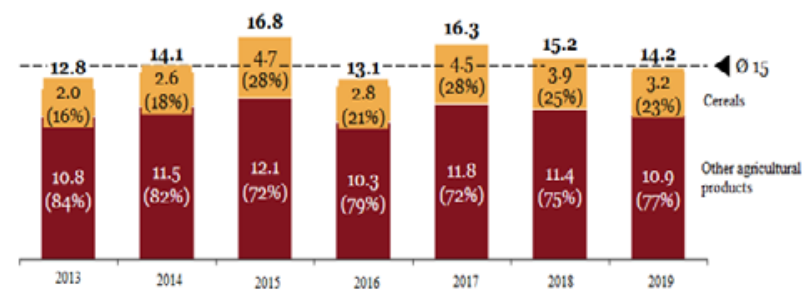

Figure 2. Reports on level of various cultures Sources: National Institute of Statistics, 2020

The transformations that Romanian agriculture has undergone during the last 30 years are best highlighted if we analyze the share of gross value added (GVA) of the agricultural sector in the gross domestic product (GDP) of Romania. At the level of 1997, the share of the agricultural sector was $22.6 \%$ of GDP, and in 2019 it had decreased to only $4.8 \%$. This decrease is largely due to the increasing importance of both industry and service sector in the national economy as a whole (the service sector increased from about 25\% of GDP in 1997 to about 60\% in 2019) and can be seen in the Figure 3.

The evolution of GVA of the agriculture in GDP (1997-2019,\%GDP)

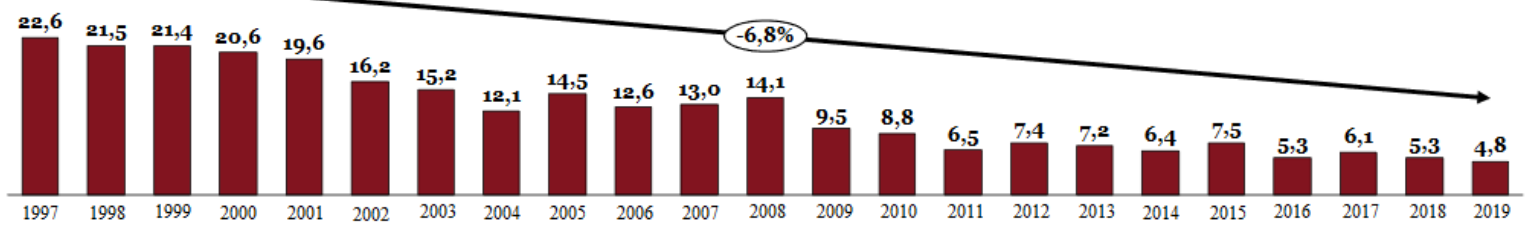

Figure 3. The evolution of agriculture GVA in the GDP

Sources: National Institute of Statistics, 2020

Until the present day, agricultural challenges were represented by technological level of agricultural works, unused fields and farmers' restrictions for getting their products (vegetables, fruits and grains) available to consumers. According to Gavrilescu and Florian (2007), the transition and change to the market economy, meant for Romania a rapid and drastic change in the relationship between two important factors: the users of the land (who became land owners) and resources (agricultural land). Nowadays few entrepreneurs and farmers integrate technology in their agricultural processes and enjoy the opportunity of fighting climate change (through irrigation during draught). The vast number of farmers that can't afford to benefit from irrigations systems work their fields on the mercy of the Government (Governmental funds) and whether. On the other hand, farmers with low bargaining power find it difficult to access distribution channels, therefore they get to sell their products for nothing. This is one of the reasons why a large number of farmers decided to dispose of their products rather than sell them for an undervalued price.

Recent pandemic events made us realize that those small farmers producing high quality goods can represent a possible solution to the challenge of satisfying the high demand of the market. Also, to provide the required amount of food from national production, farmers need Government's help turning this situation into a win-win one. The Government invests in digitization in agriculture and irrigation systems so that farmers can satisfy population's needs for goods, no longer acquiring goods from foreign markets. So, the problem is to see how these farmers can be helped and how can 
they swiftly introduce their products on the market, especially in times of crisis when customer buying habits are totally changed as they are buying large amounts of goods, therefore stocks are depleted and need to be replaced.

\subsection{Research Results}

Romania's agriculture knows a continuous development that started in the 90es. Ceausescu's regime left us a powerful agricultural infrastructure, unfortunately destroyed year by year till 2011, the last year of economic crisis. After 2011, Romanian farmers understood the need for development, and they started planting grains on their fields. Some of them infused important amounts of money in developing powerful irrigation systems in order to provide the products and goods the market required.

Even if Romanian farmers started the "engine" of agriculture, there is a long way until the day when we can say that the goods coming from Romania's agriculture will reach international markets and, most important, will decrease the volume of grains imported to Romania while meeting the needs of the national market.

\section{Research Results on the potential of Romania's agriculture in solving food challenges in times of crisis}

The attention given to farmers and agriculture nowadays is constantly increasing. As the technological revolution in the agricultural industry intensifies, the development of the sector becomes crucial both for people and for the country. Most of today's farmers have a lot of fields available for cultures and most of these fields are used to produce grains, vegetables or fruits.

In figure 4 it is shown the percentage of farmers who have fields that can sustain cultures of grains or other products and fields that could be used in agriculture.

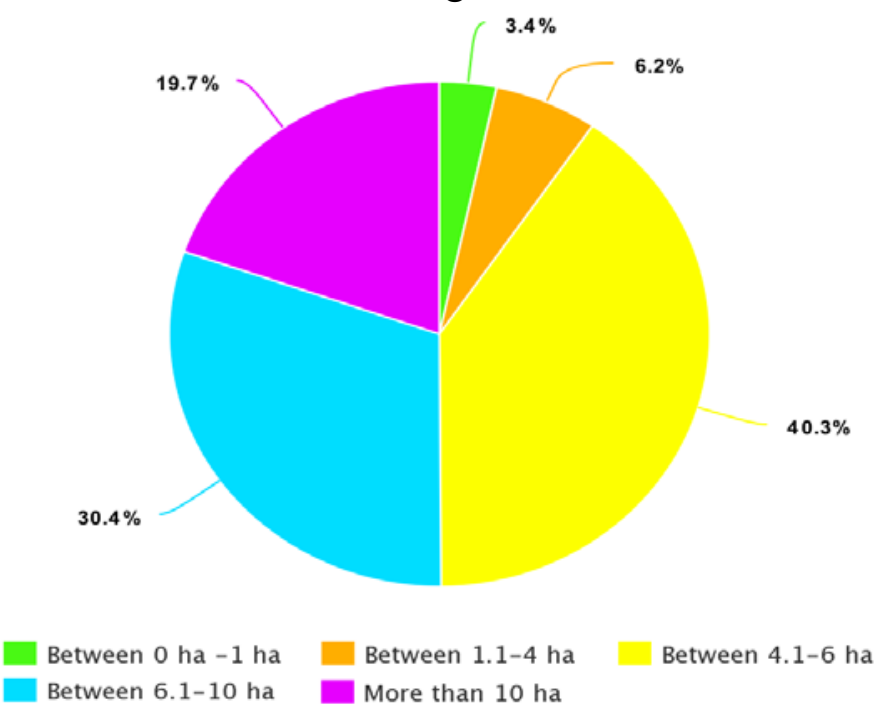

Figure 4. The available fields for agricultural activities

Sources: authors, based on the questionnaire developed with Isondaje.ro

Most of those questioned told us they own between 4.1 - 6 ha of fields available to grow various crops on. This is the alternative chosen by $40.3 \%$ of total farmers. The other alternatives chosen by a large amount of people are represented by "between 6.1-10 ha" (30.4\% of the farmers) and "more than 10 ha" (19.7\% of the farmers). The fact that there are a lot of farmers owning fields considered big in size it's a good start to ensure that in times of crisis the demand is met by national providers.

An important aspect is the percentage of fields used for agricultural purposes. Therefore, the authors tried to also find out an approximation of percentage of farmland not used by these farmers. In figure 5 farmers' answers were centralized further. 


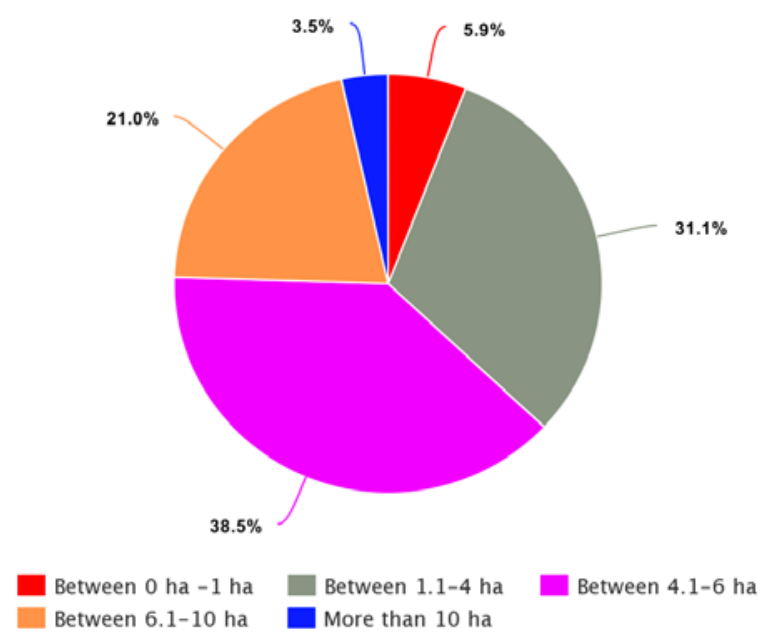

Figure 5. The number of fields not currently used

Sources: authors, based on the questionnaire developed with Isondaje.ro

Most of the questions answered that somewhere between $4.1-6$ ha are not currently used for agricultural purposes. This alternative was chosen by $38.5 \%$ of the farmers. Another alternative chosen by many of the farmers was between 1.1-4 ha which means $31.1 \%$ of the total and the last major alternative chosen by many farmers was "between $6.1-10$ ha" which means $21 \%$. The fact that there are numerous fields not currently used is due to the lack of financial resources available to farmers to develop systems that can help them in their agricultural works. Another cause to low usage of fields is the topographical position of the respective fields. There are many farmlands close to lakes or rivers without irrigation infrastructures to sustain humidity during summers with high temperatures. More than just a few farmers were confronted with too many problems for them to handle, so they chose to give up. In the figure 6 , authors identified problems farmers are confronted with.
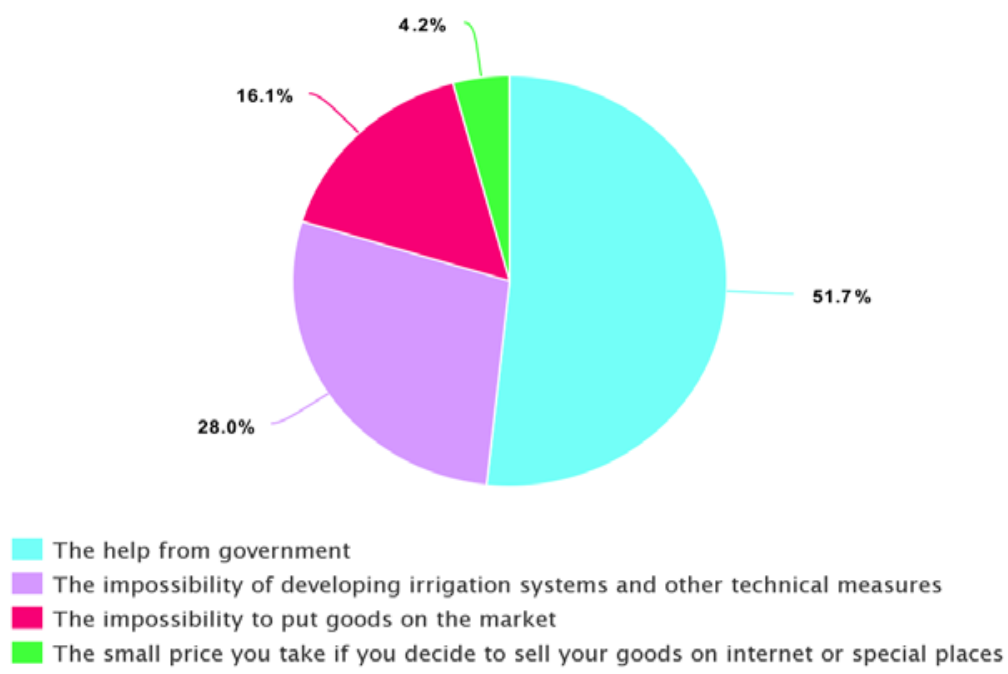

Figure 6. Problems identified by farmers on their daily activities

Source: authors, based on the questionnaire developed with Isondaje.ro

As the authors could conclude, a large number of farmers, $51.7 \%$ of the total, identified a problem in receiving help from the Government, as insufficient or non-existent. When it comes to this help, farmers need funding for irrigation systems or support to repair the old ones. Also, the Government could help them put their products on the market, but this is not seen as a priority and only 
financially powerful farmers and entrepreneurs get to have place on the market. Moreover, two other important issues that need be addressed, considered alternatives are "'the impossibility of developing irrigation systems and other technical measures" which was chosen by $28 \%$ of the total of questioned farmers and "the impossibility to place goods on the market" which was chosen by $16.1 \%$. So, the most important problems affecting agricultural activities in Romania are the financial help from the Government, the financial burden of developing irrigation systems and difficulty to place goods on the market. An answer for the first two problems is EU funding, which can help Romanian farmers implement irrigation systems on their fields and can also help them grow a technologically savvy agricultural business. So, the authors asked the farmers about contracting EU funding and the answers were centralized in figure 7.

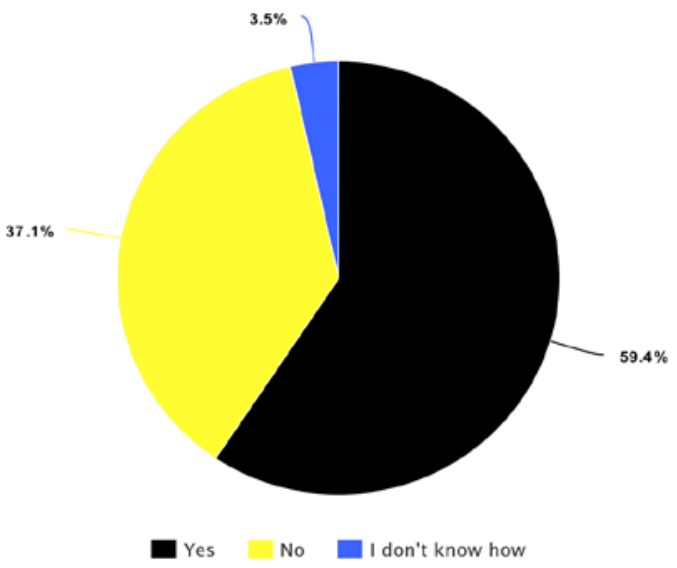

Figure 7. Number of farmers that contracted EU funding

Sources: authors, based on the questionnaire developed with Isondaje.ro

As one can notice, there is a small percentage of farmers, who do not know how to attract EU funding for their activities in the agricultural area. These farmers represented $3.5 \%$ of the total. The most chosen alternative was "yes", a percentage of 59.4\%, which means that many businesses in the agricultural sector are still working today thanks to access to EU funds. This also means that farmers can find alternatives for their businesses when there are no solutions made available by the Government. A large number of farmers chose the alternative "no", more precisely a percentage of $37.1 \%$, which can mean both that they don't know how to do it or they don't want to do it because they own financial resources to sustain their businesses without the aid of EU funds.

Now that the authors were aware of the situation, they wanted to see how the Government and big retail chains reacted in times of pandemic. More specific, they wanted to know if these two important actors asked for help from farmers in order to refill stocks of vegetables, fruits and grains. The answers were centralized in the figure 8 .

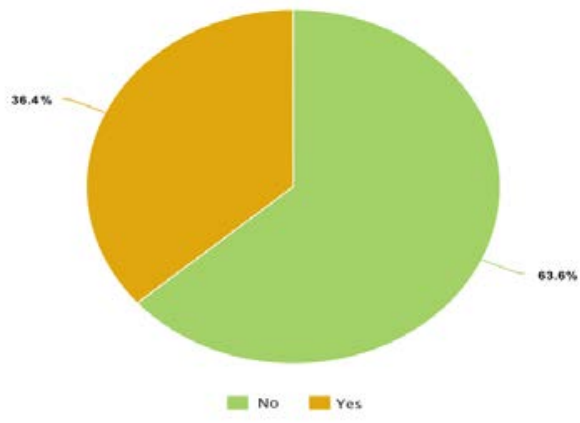

Figure 8. Number of farmers that contracted EU funding

Sources: authors, based on the questionnaire developed with Isondaje.ro 
Most of the questioned farmers responded that there were no talks during the pandemic on partnership to refill stocks for big retail chains and or Government. This alternative was chosen by a lot of farmers (63.6\% from the total). The other alternative was "yes" and was chosen by $36.4 \%$ from the total. So, the authors could see that, a viable alternative for solving a food crisis can be to buy stocks from outside Romania or from those farmers that are very powerful (with relevant bargaining power). Assuming that retail chains and Government would have accepted the goods form farmers to refill stocks, could these farmers have ensured the required quantity of goods? The answers were centralized in figure 9.

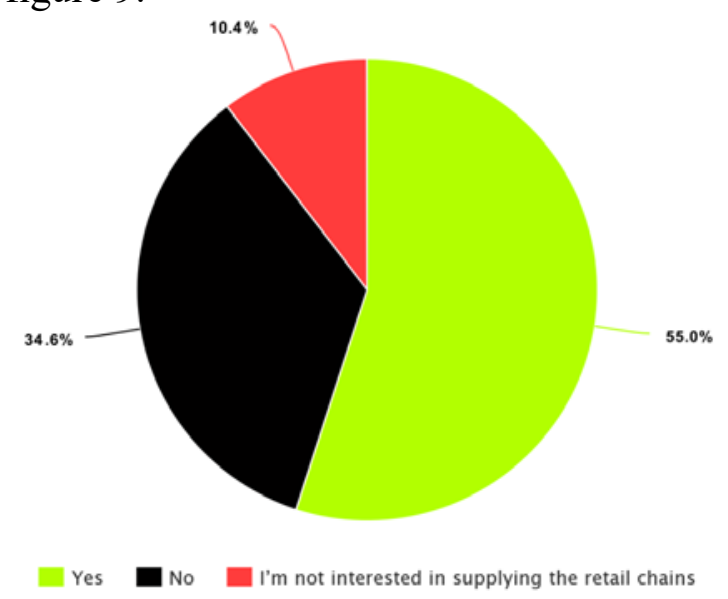

Figure 9. Availability to help refilling stocks

Sources: authors, based on the questionnaire developed with Isondaje.ro

As one can see, a large percentage of farmers said that they could have refilled the stocks for retail chains or Government if they would have been asked for help. This means 55\% from the total of questioned farmers. Other chosen alternative was "no", which means that $34.6 \%$ from the total were unable to help the retail chains or the Government whereas $10.4 \%$ said that they were not interested in supplying retail chains. As the authors found that there was enough availability to refill stocks, but no one wanted the goods, they became interested in finding out if any of the goods had been thrown away. The answers were centralized in figure 10.

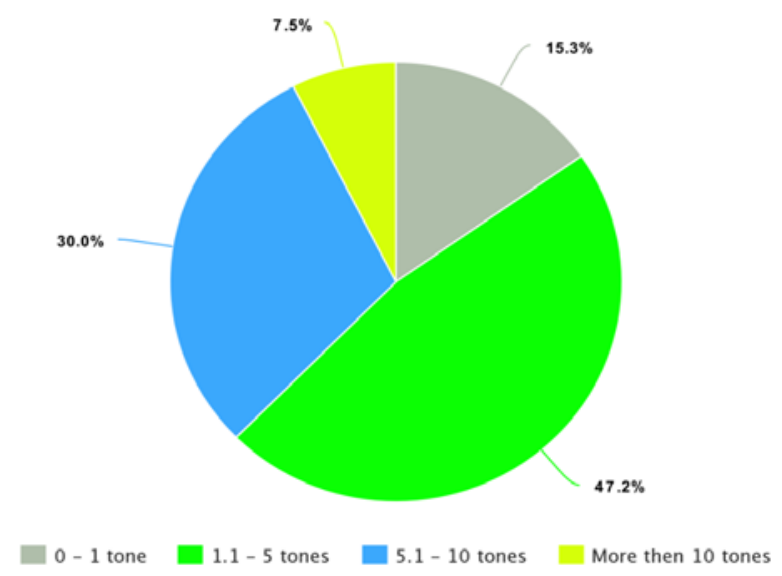

Figure 10. Tons of goods thrown away

Sources: authors, based on the questionnaire developed with Isondaje.ro

As one can see, there are tons of goods that were thrown away due to a non-existent demand from Government, retail chains and because there was no possibility for farmers to place their goods on 
the market. $47.2 \%$ of those questioned said that they throw away, annually, a quantity between 1.15 tons of goods. There is also a large percentage of farmers throwing between 5.1-10 tons of goods and $7.5 \%$ of farmers throw away, annually, more than 10 tons of goods. Only $15.3 \%$ of the farmers responded that they are throwing away between $0-1$ tons.

\section{CONCLUSIONS}

The study illustrates that the current situation of the agriculture in Romania is still under development even if many farmers own farmlands that could provide grains, vegetables and fruits for the country's population, thus generating savings through a decrease of imports. Sadly, enormous quantities of goods are being thrown away, goods that could be consumed by the population or could be exported to rebalance the trade deficit. If the Government would help farmers place their goods on the market both the population, through fresher products at a lower cost, and public finances, through lower imports, would benefit from.

Most farmers are now interested in giving a hand in respect to old irrigation systems' maintenance if not accessing $\mathrm{Eu}$ funding to build new ones and collaborate with peers towards a better development of their business. The only way to survive or thrive in such a competitive world is to work together, collaborate and access EU funding to integrate more technology, fight climatic challenges and improve processes.

To gain more bargaining power and a stronger voice, farmers in Romania should work together, access EU funding and to develop small and medium cooperatives to place their products on the internal market and even export them on the external market.

This pandemic showed us how the world is responding (or will respond) to a crisis that involves, not exclusively, but to a large extent, the food industry because of the growing need for staple aliments. In Romania, the pandemic was another supporting argument for the fact that agriculture can (and will) offer a viable solution to any potential food crisis if the Government is available to partnership and encourage local and national production.

Though at the beginning of the crisis mainly corn, oil, flour and yeast stocks were affected relevant challenges could have been avoided, despite the buying pattern based on fear, if the Government would have helped small and medium farmers develop their fields in the years before the pandemic. Higher import percentages can translate into deeper and longer financial crises that can be avoided with sustainable private and public partnership.

\section{REFERENCES}

Busuioc, A. \& Trușcă, V. (2005). Climate Change Impacts, Vulnerability Assessment and Adaption Measures, In Romania's Third National Communication on Climate Change under the United Nations Framework Convention on Climate Change, 151-182, Ministry of Environment and Water Management. Bucharest, Romania.

Ciutacu, C., Chivu, L., Andrei, V. (2015). Similarities and dissimilarities between the EU agricultural and rural development model and Romanian agriculture. Challenges and perspectives. Retrieved on September 06, 2020, from: https://www.sciencedirect.com/science/article/pii/S0264837714001859

Filon, T. (2012). The Romanian agrifood economy-performance reductive effects after five years of EU membership. Agricultural Economy Rural Development 9(1),25-45). Retrieved on August 28, 2020, from: ftp://dlib.info/opt/ReDIF/RePEc/iag/iag_pdf/AERD1201_25-45.pdf

Gavrilescu, D., \& Florian V. (2007). Economia rurală în România (Rural Economy in Romania). Terra Nostra: Iasi

National Institute of Statistics (2015). Agriculture of Romania - Indicators. Retrieved on August 20, 2020, from: https://www.ec.europa.eu/eurostat/web/europe-2020-indicators 
National Institute of Statistics (2020). Agriculture sector's development potential in Romania, Retrieved on August 24, 2020, from: https://www.media.hotnews.ro/media_server1/document2017-03-7-21648671-0-raport-pwc-agricultura.pdf

Petrescu, I. Istudor N., Ion, R., \& Sponte, M. (2014). Food security in Romania - a modern approach for developing sustainable agriculture. Sustainability 2014, 6, 8796-8807; doi: 10.3390/su61287796

PricewaterhouseCoopers Management Consultants S.R.L. (2017, March, 7). The state of Romanian agriculture in 8 points and 5 solutions ( $P$ wC report). In Hotnews.ro. Retrieved on September 05, 2020, from: https://media.hotnews.ro/media server1/document-2017-03-7-21648671-0raport-pwc-agricultura.pdf

Trușcă, V., \& Alecu, M. (2005) Romania's Third National Communication on Climate Change under the United Nations Framework Convention on Climate Change. Grue \& Hornstrup, Holstebro, 2005:28

Vincze, M. \& Kerekes, K. (2009). Impact of cap's pillars on Romanian rural employment. Applied Studies in Agribusiness and Commerce, 75-80, Budapest, Hungary: Conference Papers published by Agroinform Publishing House. Retrieved on August 24, 2020, from: http://ageconsearch.umn.edu/bitstream/53572/2/14_Vincze\%20Maria_Abstract.pdf. 